\title{
Appendix A: Guidelines for RII self-appraisal reporting
}

Several research-active universities participated in a pilot study initiated by the DG Joint Research Centres (JRC). Each university was invited to write a 'narrative with numbers' overview of their university's RII profile, according to guidelines and instructions specified in Box A1.

\section{BOX A.1 GUIDELINES FOR RII CASE STUDY REPORTING}

The general contents of each case study should align as much as possible to analytical dimensions of the Regional Innovation Impact Assessment framework available at: http://publications.jrc.ec.europa.eu/repository/ bitstream/JRC109020/jrc109020_iiu27.pdf.

Each case study should consist of the following sections and RIIA-relevant topics:

- Introduction of the university in its local or regional context;

- Regional orientation, strategic development and knowledge infrastructure;

- Education and human capital development;

- Research, technological development and knowledge transfer;

- Enterprise development and entrepreneurship.

It is recommended that each section also discusses the challenges and opportunities that the university faces, contextualised or embedded in the university's vision (or agenda) for the short-term and mid-term future.

Ideally, the case study should comprise a consistent and informative 'narrative', supplemented and strengthened by key managerial indicators and 'performance monitoring' metrics. The supporting quantitative information falls in the following categories: 'regional leadership'; 'human capital development'; 'knowledge generation and transfer'; 'entrepreneurship and enterprise development' in the context of the regional development level. The metrics provided should, where possible, clearly reflect the main trends and evolution in the performance of the university in recent years. In addi- 
tion to the quantitative indicators, qualitative evidence of impact pathways would be welcomed.

The case studies should address as many of the following key questions as possible:

- How embedded is the university in the local or regional innovation system?

- How does the university impact on, or co-develop, that system?

- How does the university contribute to diversifying the knowledge portfolio and infrastructure?

- How does the university contribute to the (further) integration into domestic or international R\&D communities or networks?

- How does the university contribute to a more vibrant sociocultural environment?

- How does the university contribute to job creation and upgrading the economic structure and performance?

- How does the state legislation and the university regulations enhance or hamper the knowledge transfer process and the entrepreneurial development?

- What are the main challenges that the university faces and what are the ways for overcoming them? 